\title{
Article \\ Development of an End-Toothed Disc-Based Quick-Change Fixture for Ultra-Precision Diamond Cutting
}

\author{
Xuesen Zhao $\mathbb{1}$, Xiangwu Cui, Zhenjiang Hu, Qiang Zhang and Tao Sun * \\ Center for Precision Engineering, Harbin Institute of Technology, Harbin 150001, China; \\ zhaoxuesen@hit.edu.cn (X.Z.); xiangwucui@foxmail.com (X.C.); lyhoo@hit.edu.cn (Z.H.); \\ qiangzi0814@163.com (Q.Z.) \\ * Correspondence: taosun@hit.edu.cn
}

Citation: Zhao, X.; Cui, X.; Hu, Z.; Zhang, Q.; Sun, T. Development of an End-Toothed Disc-Based Quick-Change Fixture for Ultra-Precision Diamond Cutting. Machines 2021, 9, 257. https:// doi.org/10.3390/machines9110257

Academic Editor: Angelos

P. Markopoulos

Received: 24 September 2021

Accepted: 27 October 2021

Published: 29 October 2021

Publisher's Note: MDPI stays neutral with regard to jurisdictional claims in published maps and institutional affiliations.

Copyright: (C) 2021 by the authors. Licensee MDPI, Basel, Switzerland. This article is an open access article distributed under the terms and conditions of the Creative Commons Attribution (CC BY) license (https:/ / creativecommons.org/licenses/by/ $4.0 /)$.

\begin{abstract}
With its standardized and unified interface, the quick-change fixture is an important part for maintaining high efficiency without compensation of precision in the metal-turning process because it can conveniently realize high-precision repeated clamping and multi-station conversion without complex positioning and adjustment steps. However, the existing quick-change fixture products and related research cannot fully meet the needs of repeatability and applicability raised from ultra-precision, single-point diamond turning with ultra-high accuracy and ultra-small depth of cut. In this paper, we develop a quick-change fixture for ultra-precision diamond turning, in which the end-toothed disc acts as the positioning element. Specifically, the main parameters of two key components of the end-toothed disc and slotted disc spring are calculated analytically to ensure the positioning accuracy of the designed fixture used in the rotation condition, which is further ensured by controlling the machining tolerance of the tooth profile of the end-toothed disc. Additionally, finite element simulations are performed to investigate the static and modal states of the quick-change fixture, which demonstrate a maximum deformation of about $0.9 \mu \mathrm{m}$ and a minimum natural frequency of $5655.9 \mathrm{~Hz}$ for the designed fixture. Two high-precision sensors are used to detect the radial jump and end run-out values after repeated clamping actions, which are employed to verify the repetitive positioning accuracy of the fixture. Subsequent finite-element simulation of the clamping of small-diameter copper bar, as well as the diamond turning experiment, jointly demonstrate that the designed fixture can achieve a precision of $1 \mu \mathrm{m}$. Current work provides an effective quick-change fixture to reduce the deformation of a weak-stiffness workpiece caused by clamping deformation in ultra-precision diamond cutting.
\end{abstract}

Keywords: ultra-precision diamond cutting; quick-change fixture; end-toothed disc; repetitive positioning accuracy

\section{Introduction}

Precision is one of the most important aspects of manufacturing, and high-precision manufacturing is one of the characteristics of the extreme manufacturing era $[1,2]$. While the workpiece, machine tool, and cutting tool are closely connected with each other in the metal-turning process, the quick-change fixture has become an indispensable and important part that strongly affects the achievable accuracy of the turning process $[3,4]$. The fixture design for micro/nano machining is also greatly needed due to the increasing demand for precision machining of micro/nano parts, which has dramatic differences from conventional machining in terms of material removal depth, utilized cutting tool, and processing techniques [5].

There are inevitable requirements of repeated clamping and transposition in the mass production of parts by turning operation, and the errors introduced by the repeated clamping cannot be ignored in ultra-precision machining [6]. To solve this problem, the quick-change fixture provides a feasible solution [7]. The basic composition of the quickchange fixture can be described as a female interface fixedly connected with the machine 
tool or working platform and a male interface connected with the workpiece to move with the workpiece at the same time. The male and female interfaces are matched with each other's standardized positioning benchmark, and the clamping of the male and female interfaces is ensured through an integrated or independent structure. The quick-change fixture provides a unified and standardized positioning "zero point" for the workpiece through the standardized interface, which makes the design, processing, and inspection of datums unified. Furthermore, the realization of the rapid changing through convenient uncoupling and locking provides an important guarantee for reducing the clamping error and shortening the clamping time.

The quick-change fixture was first introduced by The Swedish Company System 3R in the early 1970s and played a prominent role in the turning processes [8-10]. Since then, similar products have also been developed, most of which have a repeat positioning accuracy of 2-5 $\mu \mathrm{m}$. Kartik et al. [11,12] proposed a dual-purpose positioning fixture based on three high-precision steel balls to achieve high positioning accuracy with good repeatability and high stiffness stability. Olivari et al. [13] compared the main quick-change fixture systems and briefly described their working principles and applications. Ayatolahi et al. [14] developed a demonstrator for an intelligent clamping tower based on a quick-change fixture, which was equipped with temperature sensors. Sitzberger et al. [15] found that the hydraulic-expansion-holder-based quick-change fixture provides a reference for the application of the quick-change fixture in optical precision parts processing. Sulz et al. [16] carried out relevant research work on detecting and compensating for the thermal deformation of the quick-change fixture system, aiming for solving the problem of temperature-change-induced deterioration of machining accuracy. Denkena et al. [17] proposed a design and integration method of a strain sensor applied to a quick-change fixture system that can monitor the process and state of the fixture, and demonstrated that this method has the potential of automatic long-term detection of device fatigue failure. Based on an end-toothed disc, Zhao et al. [18] proposed a novel positioner fixture with high repeated positioning accuracy and high stiffness. However, the experiment was completed in a static environment, which is not sufficient to simulate the real situation of the metal-cutting state.

The quick-change fixture has also been widely used in flexible manufacturing systems (FMSs), in which the use of quick-change fixtures provides a guarantee for rapid reconfiguration and convenient assembly of pallets without halting the system $[19,20]$. In particular, the quick-change fixture has the ability to connect machine tools with different parts, which is helpful to realize the joint evolution of products, processes, and production systems [21,22]. Although the quick-change fixture has been developed for about 50 years, most of the previous work mainly focuses on the product's introduction and application, and the work on its principle analysis, design, and manufacturing is limitedly reported. In particular, there is little research work reported on quick-change fixtures for ultra-precision diamond cutting. Since the material-removal depth of workpiece material in diamond cutting is in the range of some micrometers, even submicron, the accuracy of a quick-change fixture has a more pronounced impact on the machining accuracy than that in conventional machining.

Therefore, aiming at solving the problem of introducing errors in repeated clamping in ultra-precision, single-point diamond turning and detection of complex micro parts, in this work, we develop a high-precision quick-change fixture based on an end-toothed disc, which possesses the advantages of high positioning accuracy, good positioning rigidity, and large bearing capacity. Additionally, the effectiveness of the as-developed quick-change fixture is validated by both finite-element (FE) simulation of clamping and experiment of diamond turning of a small-diameter copper bar. 


\section{Structural Design and Simulation Analysis of the Quick-Change Fixture}

\subsection{The Structural Design of the Quick-Change Fixture}

The whole structure of the quick-change fixture designed in this paper is divided into three parts as follows: component, fixed component, and locking mechanism, respectively. The schematic diagram of each part in two states of locking and unlocking after assembly is shown in Figure 1. The workpiece and other fixtures are connected with the following components. Fixed components are installed on the working plane (such as the lathe spindle). The following components and the fixed components are positioned through the end-toothed disc and locked by the locking mechanism. The internal structure diagram and design details of the fixture are shown in Figure 2. The locking mechanism adopts the method of steel ball and cone, and the locking force is provided by the slotted disc spring. The disc spring is used for its high stiffness and strong shock-absorption capacity. The axial space required by the disc spring is smaller than that of the ordinary cylindrical spiral spring, which reduces the impact caused by the centripetal force when rotating at high-speed.

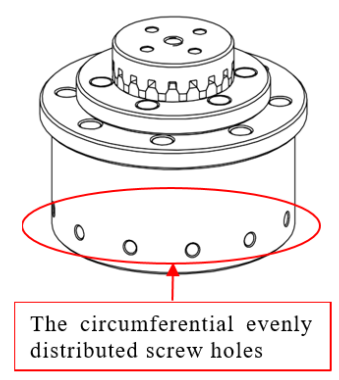

(a)

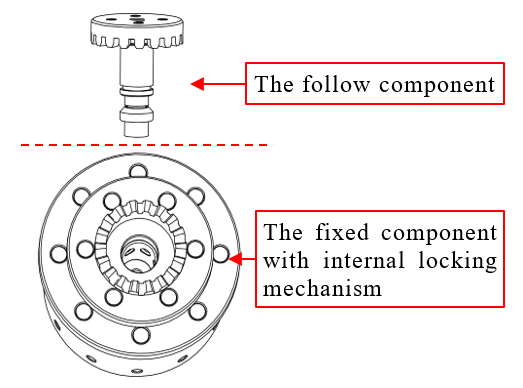

(b)

Figure 1. Schematic diagram of two working states of the designed fixture. (a) Locking state; (b) unlocking separation status.

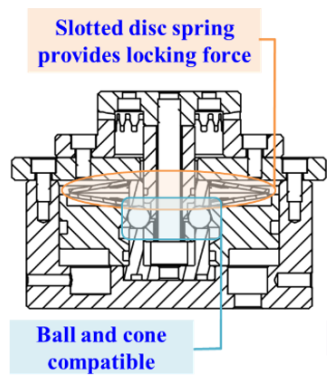

(a)

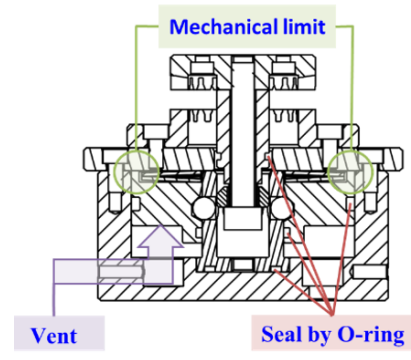

(b)

Figure 2. The internal structure of the designed fixture. (a) Locking state; (b) unlocking separation status.

The quick-change fixture designed in this work adopts the mechanical locking mode, which makes it reliably work without the introduction of lines of oil, gas, electricity, etc. At the same time, the whole fixture is designed with rotary symmetry structure, and the circumferential evenly distributed screw holes are reserved for adjusting the dynamic balance. The above characteristics show that the designed quick-change fixture can work not only in the static state but also in the working condition of a high-speed rotating spindle. 


\subsection{Parameter Design of Key Components of the Quick-Change Fixture}

2.2.1. Tooth Profile Parameter Design and Tolerance Formulation of the End-Toothed Disc

The working accuracy of the end-toothed disc is closely related to the contact accuracy of the tooth surface. Additionally, the design of the tooth profile parameters directly affects the machining difficulty and machining precision of the end-toothed disc. The tooth profile parameters of the end-toothed disc are mainly designed with reference to Chinese standard JB/T 4316.1-2011 and relevant manuals. The final design results of the main parameters are listed in Table 1, and other parameters can be calculated by relevant formulas.

Table 1. The design results of the main parameters of the end-toothed disc.

\begin{tabular}{|c|c|c|}
\hline Parameters & Cardinal Principle & Results \\
\hline $\begin{array}{l}\text { Diameter } \\
(D)\end{array}$ & $\begin{array}{l}\text { Determined according to the size of the space, } \\
\text { and the size should be moderate }\end{array}$ & $50 \mathrm{~mm}$ \\
\hline $\begin{array}{l}\text { Number of teeth } \\
(Z)\end{array}$ & $\begin{array}{l}\text { The greater the number of teeth, the better the } \\
\text { effect of error equalization, but too many teeth } \\
\text { will increase the difficulty of machining }\end{array}$ & 18 \\
\hline $\begin{array}{l}\text { Tooth profile angle } \\
\qquad(\Phi)\end{array}$ & $\begin{array}{l}\text { The smaller the value is, the better the } \\
\text { self-locking performance. However, if the } \\
\text { value is too small, the tooth will become } \\
\text { thinner and deeper, which will affect the } \\
\text { stiffness and error. The common values are } 40^{\circ} \text {, } \\
\qquad 60^{\circ} \text {, and } 90^{\circ}\end{array}$ & $60^{\circ}$ \\
\hline $\begin{array}{l}\text { Dip angle of groove bottom } \\
\qquad(\alpha)\end{array}$ & $\begin{array}{l}\text { Calculation by accurate tooth profile formula } \\
\qquad \alpha=\arctan \frac{\tan \left(90^{\circ} / Z\right)}{\tan (\varphi / 2)}\end{array}$ & $8^{\circ} 37^{\prime}$ \\
\hline $\begin{array}{l}\text { Tooth length } \\
\qquad(F)\end{array}$ & Generally based on experience & $6 \mathrm{~mm}$ \\
\hline $\begin{array}{l}\text { Working tooth height } \\
\qquad\left(h^{\prime}\right)\end{array}$ & $\begin{array}{l}\text { Refer to the size of the theoretical tooth height } \\
\text { to determine }\end{array}$ & $2 \mathrm{~mm}$ \\
\hline
\end{tabular}

The meshing height error $\Delta H_{i}$ of the end-toothed disc, which is caused by the cumulative error of tooth pitch $\Delta t_{i}$, the tooth trace error $\Delta \beta_{i}$, and the tooth profile half-angle error $\Delta \Phi_{i}$, is expressed in Equation (1):

$$
\Delta H_{i}=\Delta H_{t i}+\Delta H_{\beta i}+\Delta H_{\Phi i}=\frac{1}{2} \cot \frac{\Phi}{2} \cdot \delta t_{i}+\frac{1}{2} F \cot \frac{\Phi}{2} \cdot \delta \beta_{i}+\frac{h^{\prime}}{\sin \Phi} \cdot \delta \Phi_{i}
$$

where $\Delta H_{t i}, \Delta H_{\beta i}, \Delta H_{\Phi i}$ are the meshing height errors caused by three-tooth-profile machining errors, $F$ is the tooth length, $h^{\prime}$ is the working tooth height, and $\Phi$ is the tooth profile angle. The allowable meshing height error of the end-toothed disc is set as $\delta_{H}$. The limit tolerance of the cumulative error of tooth pitch, the tooth trace error, and the tooth profile half-angle error is set as $T_{t}= \pm T_{1}, T_{\beta}= \pm T_{2}, T_{\Phi}= \pm T_{3}$, respectively. According to Equation (1), the qualifying condition of the end-toothed disc is $\Delta H_{t i}+\Delta H_{\beta i}+\Delta H_{\Phi i} \leq \delta_{H}$. The error value assigned by the meshing height error $\delta_{H}$ to the three-tooth-profile machining error is, respectively, marked as $\delta_{H 1}, \delta_{H 2}, \delta_{H 3}$, where $\delta_{H 1}+\delta_{H 2}+\delta_{H 3}=\delta_{H}$. Then, the error values can be expressed by Equation (2):

$$
\left\{\begin{array}{l}
\frac{1}{2} \cot \frac{\Phi}{2} \cdot \delta t_{i} \leq \frac{1}{2} \cot \frac{\Phi}{2} \cdot 2 T_{1} \leq \delta_{H 1} \\
\frac{1}{2} F \cot \frac{\Phi}{2} \cdot \delta \beta_{i} \leq \frac{1}{2} F \cot \frac{\Phi}{2} \cdot 2 T_{2} \leq \delta_{H 2} \\
\frac{h^{\prime}}{\sin \Phi} \cdot \delta \Phi_{i} \leq \frac{h^{\prime}}{\sin \Phi} \cdot 4 T_{3} \leq \delta_{H 3}
\end{array}\right.
$$


So, the maximum allowable errors can be expressed by Equation (3):

$$
\left\{\begin{array}{l}
T_{1} \leq \tan \frac{\Phi}{2} \cdot \delta_{H 1} \\
T_{2} \leq \frac{1}{F} \tan \frac{\Phi}{2} \cdot \delta_{H 2} \\
T_{3} \leq \frac{\sin \Phi}{4 h^{\prime}} \cdot \delta_{H 3}
\end{array}\right.
$$

Since this paper focuses on the repeatable positioning accuracy rather than the positioning accuracy, and considering the time and economic cost of the processing, the initial design of the meshing height error of the end-toothed disc is chosen as $5 \mu \mathrm{m}$. According to the above analysis, the meshing height error assigned to the cumulative pitch error, tooth direction error, and tooth profile half-angle error is $\delta_{H 1}=4 \mu \mathrm{m}, \delta_{H 2}=\delta_{H 3}=0.5 \mu \mathrm{m}$, respectively. Then, the maximum allowable errors can be obtained from Equation (4):

$$
\left\{\begin{array}{l}
T_{1} \leq \tan \frac{\Phi}{2} \cdot \delta_{H 1}=\tan 30^{\circ} \times 4 \approx 2.31 \mu \mathrm{m} \\
T_{2} \leq \frac{1}{F} \tan \frac{\Phi}{2} \cdot \delta_{H 2}=\frac{1}{6} \times \tan 30^{\circ} \times 0.5 \approx 2.89^{\prime} \\
T_{3} \leq \frac{\sin \Phi}{4 h^{\prime}} \cdot \delta_{H 3}=\frac{\sin 60^{\circ}}{4 \times 2} \times 0.5 \approx 3.25^{\prime}
\end{array}\right.
$$

According to the above calculation results, the limit tolerance of the cumulative error of the tooth pitch in preliminary design is $\pm 2 \mu \mathrm{m}$, the limit tolerance of tooth direction error is $\pm 2.5^{\prime}$, and the limit tolerance of the tooth profile half-angle error is $\pm 3^{\prime}$. The final machined end-toothed disc is shown in Figure 3. To minimize the impact of eccentricity on the accuracy of the fixture, the designed end-toothed disc itself has a characteristic of self-centering. Furthermore, since the tooth profile of the designed end-toothed disc is a standard Hess tooth and its parameters are calculated by an accurate tooth profile formula, the end-toothed disc can be matched not only with a pair of upper and lower-gear discs but also with two upper-gear discs or two lower-gear discs. Additionally, the tooth profile parameters of the end-toothed disc are calculated by the accurate tooth profile formula, which can ensure that the tooth thickness of any concentric circle on the pitch plane is equal to the tooth groove width so as to ensure that the upper-gear disc and the lower-gear disc can match well. Thus, the end-toothed disc designed in this work has a good centrality.

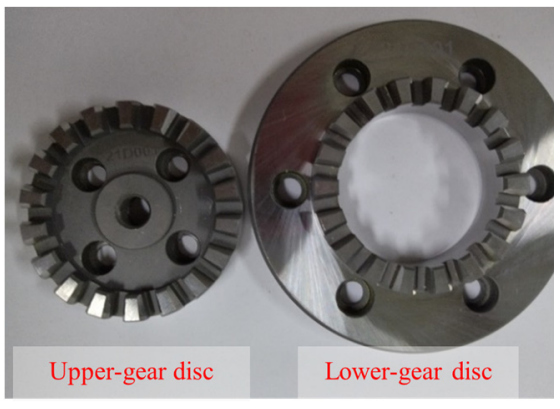

(a)

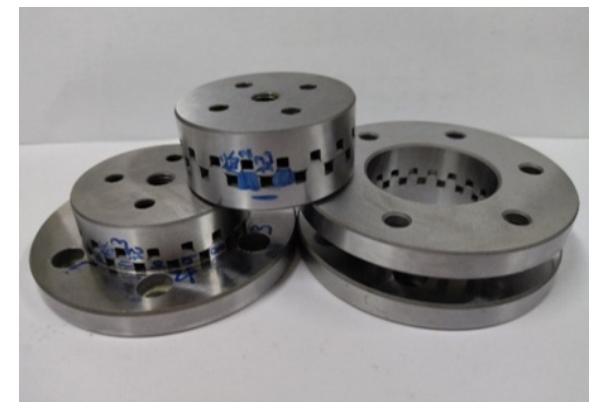

(b)

Figure 3. The fabricated end-toothed disc. (a) Matched with a pair of upper- and lower-gear discs; (b) matched with two upper-gear discs or two lower-gear discs.

\subsubsection{Parameter Design of the Slotted Disc Spring}

The mechanical locking method of the designed quick-change fixture is realized by the spring. The design of the spring is related to the mechanical locking effect, which directly affects the realization of the pneumatic unlocking function. Referring to the relevant mechanical design manual and considering comprehensively, it is necessary to adopt the method of combining two slotted disc springs so that the force of the slotted disc spring remains unchanged, and the stroke of each slotted disc spring can be shortened by half. The final design parameters are listed in Table 2. 
Table 2. Design results of main parameters of the slotted disc spring.

\begin{tabular}{cc}
\hline Parameters & Results \\
\hline Outside diameter $(D)$ & $70 \mathrm{~mm}$ \\
\hline Inside diameter $(d)$ & $29 \mathrm{~mm}$ \\
\hline Slotting diameter $\left(D_{m}\right)$ & $47 \mathrm{~mm}$ \\
\hline Thickness $(t)$ & $1.25 \mathrm{~mm}$ \\
\hline Free height $\left(L_{0}\right)$ & $5 \mathrm{~mm}$ \\
\hline Small end width $\left(B_{1}\right)$ & $3 \mathrm{~mm}$ \\
\hline
\end{tabular}

The characteristic curve of the slotted disc spring is shown in Figure 4. The load is $341.887 \mathrm{~N}$ and $894.33 \mathrm{~N}$ when the compression distance is $0.5 \mathrm{~mm}$ and $3 \mathrm{~mm}$, respectively. The material of the slotted disc spring is thermally treated 60Si2MnA spring steel. The allowable stress is between $1400 \mathrm{MPa}$ and $1600 \mathrm{Mpa}$, which means the designed slotted disc spring meets the requirements of allowable stress. The picture of the finally obtained slotted disc spring is shown in Figure 5.

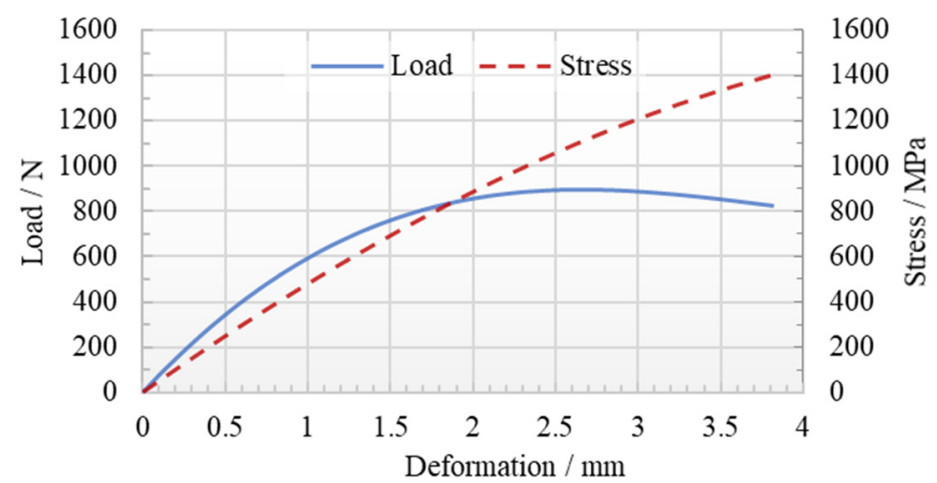

Figure 4. The characteristic curve of the designed slotted disc spring.

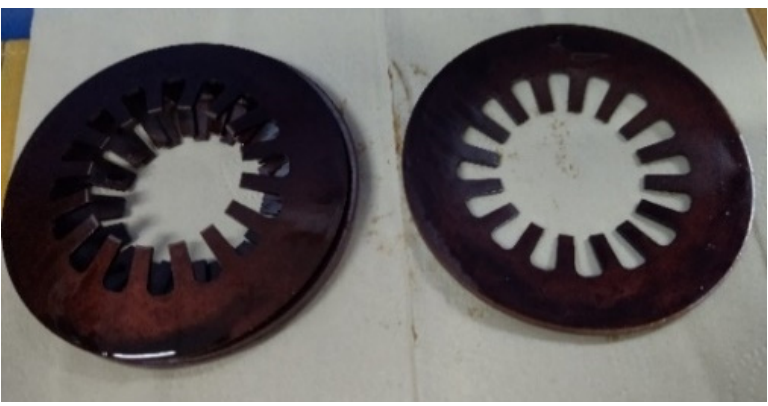

Figure 5. The fabricated slotted disc spring.

\subsection{Static and Modal Analysis of the Quick-Change Fixture}

FE simulation of the quick-change fixture is also performed based on NX Nastran, which is a rigorously verified FEA solver that has been in widespread use for decades [23]. The CAE system by Siemens PLM Software is used for computerized engineering analysis of designed parts, which enables the calculation of both static and dynamic linear and nonlinear problems of engineering analysis [24]. Figure 6 shows the FE simulation result of meshing of the idealized parts of the designed fixture, in which chamfering and dynamic balance screw holes in the base are removed. The mesh adopts a 3D tetrahedron type, and the mesh size is further refined to obtain improved simulation results. The material of the end-toothed disc is set as $40 \mathrm{Cr}$ steel, and the mesh size is $0.8 \mathrm{~mm}$. For other parts, the material is selected as 7075 aluminum alloy, and the mesh size is $1 \mathrm{~mm}$. 


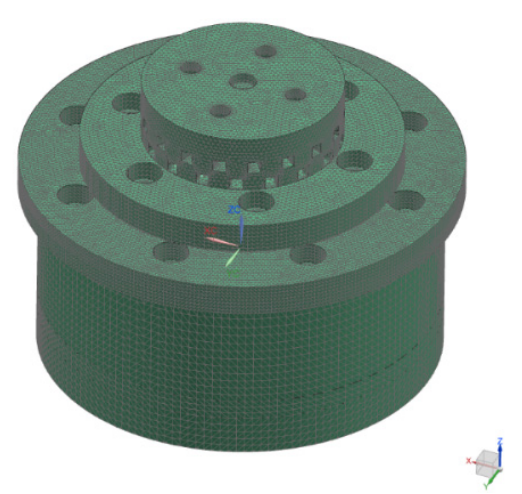

Figure 6. Mesh generation results of the idealized model.

Four loading conditions, including locking force, gravity, rotation (1000 rpm), and torque (500), are simulated to explore the force of the designed quick-change fixture. Additionally, a pressure of $400 \mathrm{~N}$ (greater than $341 \mathrm{~N}$ ) is applied to the locking slider when the locking force is applied. Only the rotation freedom of the base bottom in the z-direction is released, and the other five freedoms are restricted so that only freedoms of movement in the $\mathrm{z}$-direction and rotation of the locking slider are allowed. At the same time, other parts are connected by surface adhesion according to the assembly relationship. The deformation contour of the model under the coupling action of the four loading conditions above is shown in Figure 7, in which the maximum deformation occurs at the center screw hole of the upper-gear disc, and the maximum deformation is about $0.9 \mu \mathrm{m}$. From the point of view of clamping-force-induced deformation, the introduction of the designed quick-change fixture has a trivial impact on the machining accuracy of the parts.

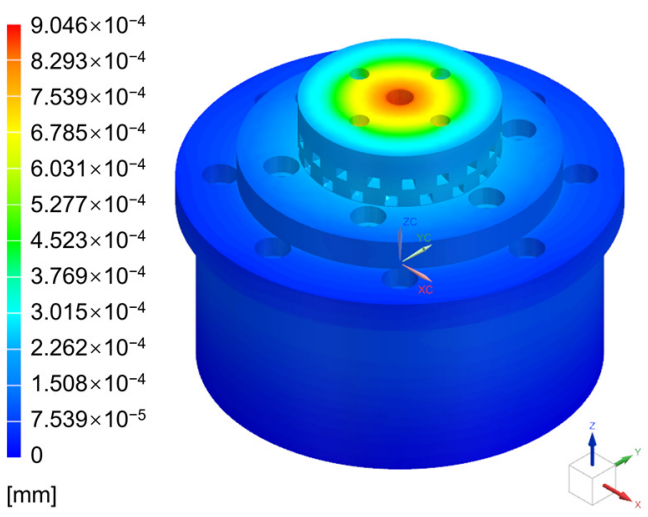

Figure 7. Deformation contour of the model under four loads.

The modal analysis of the designed fixture by FE simulation is also performed. Loadfree conditions are imposed on the model, and fixed constraints are imposed on the bottom surface of the base. Other parts are connected by surface adhesion according to the assembly relationship. After the solution is submitted, the first six modes of the fixture are obtained, in which the deformation is magnified for observation, as shown in Figure 8.

It can be seen from Figure 8 that the deformation forms of mode 1 and mode 2 are the same, and the frequencies of the two modes are very similar, but the deformation directions are different in the $\mathrm{X}$ and $\mathrm{Y}$ directions. It can be judged that there are two different vibration forms of the same vibration mode of the fixture, and the corresponding frequency is the first-order resonance frequency. The case of modes 5 and 6 is similar to the above. The deformation of mode 3 and mode 4 are axial rotation and axial tension, respectively, and the modal frequencies are also different, so they are two different vibration modes. In the simulation results, the minimum frequency is relatively high as $5655.9 \mathrm{~Hz}$, which indicates that the overall stiffness of the fixture is also high. 


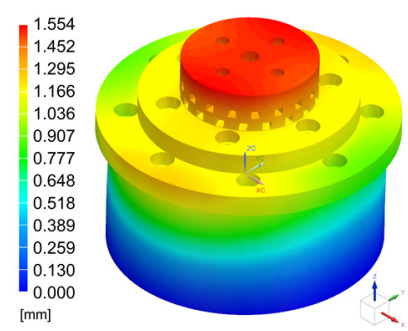

(a)

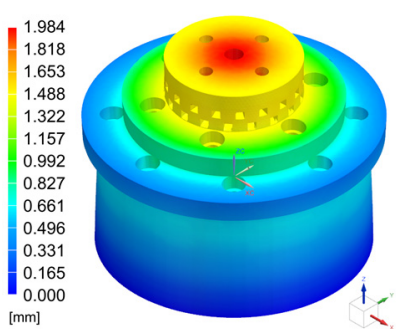

(d)

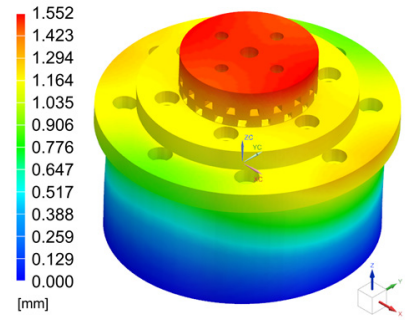

(b)

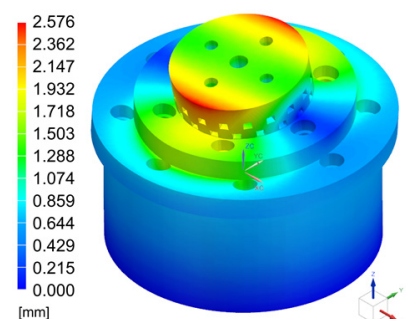

(e)

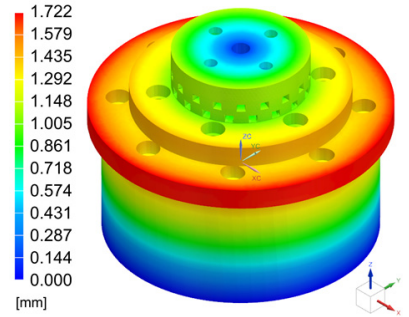

(c)

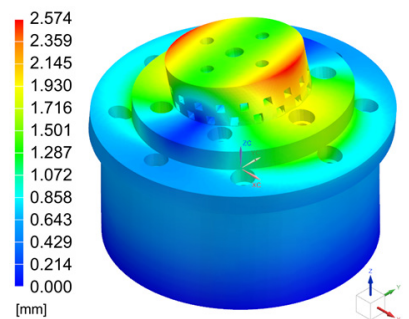

$(\mathbf{f})$

Figure 8. The deformation contour of the first six modes of the model. (a-f) Mode 1-6, and their natural frequencies are 5655.9, 5659.82, 10,474.1, 11,072.5, 14,147.6, and 14,155.0 Hz, respectively.

\section{Verification of Repetitive-Positioning Accuracy of the Quick-Change Fixture}

All the verification experiments in this work are carried out on the four-axis ultraprecision lathe developed by the Center for Precision Engineering, Harbin Institute of Technology, China. The picture of the designed fixture after assembly is shown in Figure 9a,b. The parts with a large radius can be directly connected with the upper-gear disc in the following component by screws. At the same time, in order to facilitate the installation of cylindrical parts with small diameters, a special fixture is designed based on ER Chuck. The final installation of the fixture is shown in Figure 9c.

\subsection{Experimental Scheme and Preparation Work}

In order to detect the repeated accuracy of the designed fixture, two high-precision sensors are used to simultaneously detect the radial jump and end jump of the uppergear disc. The circular jump is detected by the Swiss TESA GT31 (Renens, Switzerland) lever displacement sensor and analog quantity measuring instrument TOP400AS with a resolution of $0.01 \mu \mathrm{m}$, as shown in Figure 10a. We note that the TESA probe is not used in the measurement of run-out, as it may scratch the surface and affect the measurement accuracy. Additionally, the detection of end jump adopts the French STIL spectral confocal sensor CCS Prima controller and CL1-MG140 optical pen with a minimum resolution of distance mode of $5 \mathrm{~nm}$, as shown in Figure 10b. The detection data of the above two sensors can be directly displayed and stored in the industrial computer of the machine tool, and the stored data are further processed and analyzed with the help of powerful and diverse library functions in Python. The static measurement results of the spectral confocal sensor show that the data fluctuation range is about $0.2 \mathrm{~mm}$ in the measurement time of $70 \mathrm{~s}$, which may be affected by temperature, stress release of the clamp holding the sensor, and signal line interference. The jump values of the upper-gear disc after repeated clamping actions are compared, which show that the smaller the variation ranges, the higher the repetitive positioning accuracy of the fixture. Because the run-out value is a relative value rather than an absolute value, and the detection time is relatively short, it can reduce the influence of machine tool motion accuracy, external environment, sensor repetition accuracy, and other factors. 


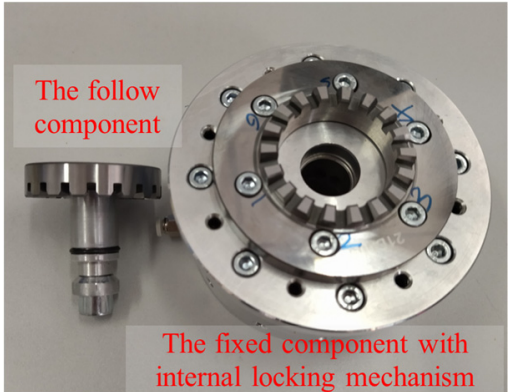

(a)

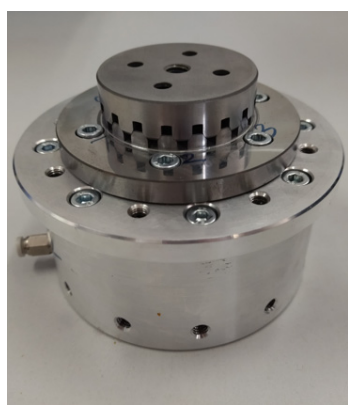

(b)

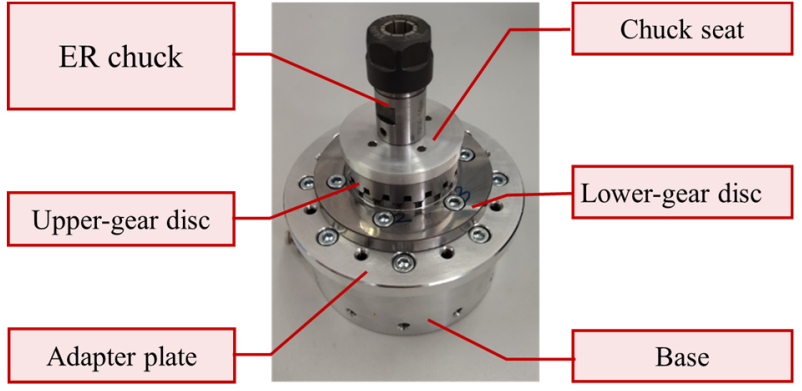

(c)

Figure 9. The fabricated quick-change fixture. (a) Unlocking state; (b) locking state; (c) the final installation configuration.

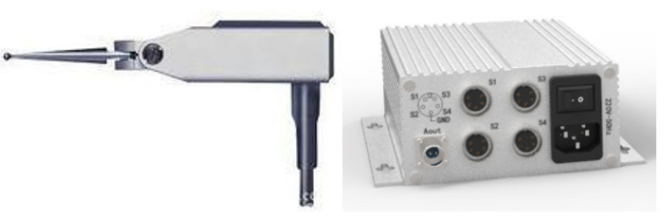

(a)

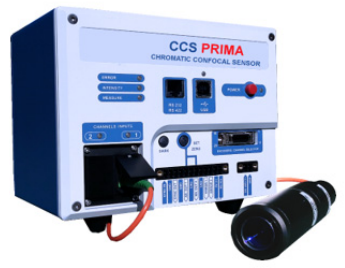

(b)

Figure 10. The sensors used in the experiment. (a) TESA GT31 displacement sensor; (b) STIL spectral confocal sensor.

In the experiment, the radial jump and end jump of the lower-gear disc are ensured to be within $5 \mu \mathrm{m}$ at the same time. These errors can be regarded as installation errors that do not affect the detection of repetitive positioning accuracy. Since there are high-frequency noise and outliers in the measured data, the original data are smoothed by using the Savitzky-Golay filter-smoothing function of the SciPy library in Python.

After the lower-gear disc is installed, the upper-gear disc can be installed and formally tested. The position of the sensor is shown in Figure 11. The detection process is to take the zero point of the $\mathrm{C}$-axis of the machine tool as the initial point, with the sampling time interval of the sensor as $25 \mathrm{~ms}$. In the run-out measurement, the C-axis rotates $1080^{\circ}$ in $54 \mathrm{~s}$ under the speed of $20^{\circ} / \mathrm{s}$. After the measurement, the current machine tool coordinates are recorded, and then the machine tool is moved to keep the fixture away from the sensor. In the following repeated clamping actions, the fixture is returned to the recorded machine tool coordinates to test again according to the above steps.

\subsection{Experimental Process and Analysis}

The end-toothed disc used in this paper has 18 teeth, so there are 18 meshing positions when a pair of end-toothed discs are matched. In order to facilitate the study of repetitive positioning accuracy at different meshing positions, the 18 teeth of the lower-gear disc are, respectively, marked 1-18 with a marker, while only a groove of the upper tooth disc is marked, as shown in Figure 11. 


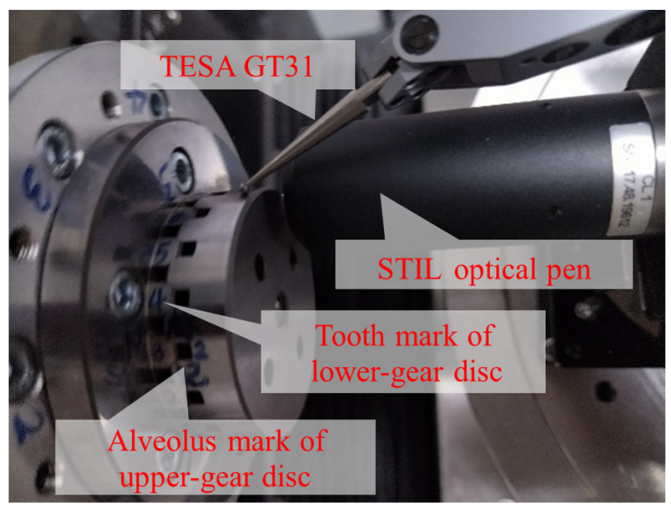

Figure 11. Configuration of the detection process.

The group 1 experiment used the same pair of end-toothed discs (upper-gear disc 1 and lower-gear disc 1) to cooperate with each other. Firstly, the repetitive positioning accuracy of the two toothed discs in the same meshing position (hereinafter referred to as repeated clamping after non-rotating) is tested. The marked tooth groove of the upper-gear tooth disc 1 is randomly selected to match with the tooth marked 4 of the lower-gear disc 1 , and the toothed disc is matched in this position every time for repeated clamping. The results after 15 repeated clamping actions and tests are shown in Figure 12. It is seen from Figure 12 that when the same pair of gear disks are matched and the meshing position is relatively unchanged, the variation range of the clamp's radial jump value and end jump value of the fixture is less than $1 \mu \mathrm{m}$ after repeated clamping. Then, the run-out of the upper-gear disc is tested when there is relative rotation at the meshing position of the two gear plates (hereinafter referred to as repeated clamping after rotating).

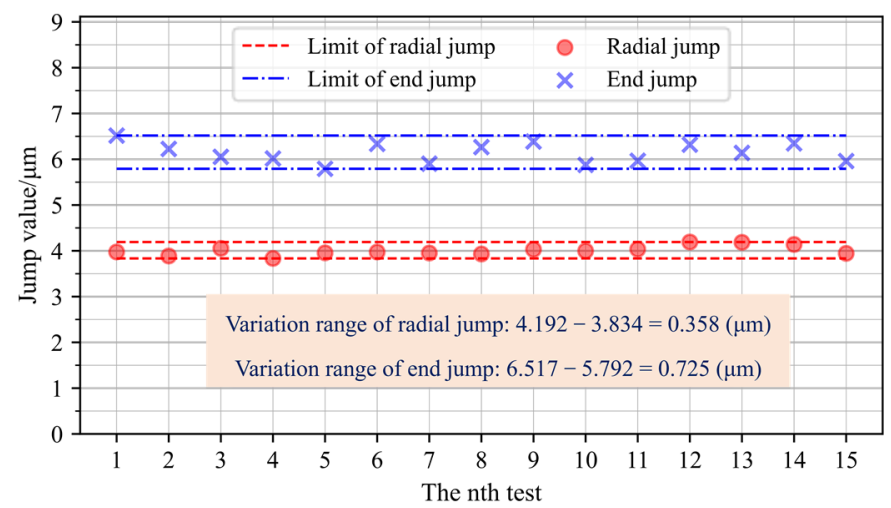

Figure 12. Test results of experimental group 1 without rotating teeth.

The measurement process is to first fit the marked tooth groove of the upper-gear disc 1 with the tooth marked 1 of the lower-gear plate 1 , and then fit the marked tooth groove of the upper-gear disc 1 with the teeth marked from 2 to 18 of the lower-gear plate 1 through repeated clamping, which forms a completed measurement cycle. Three cycles are carried out, and the final measurement results and statistical results are shown in Figures 13 and 14, respectively. 


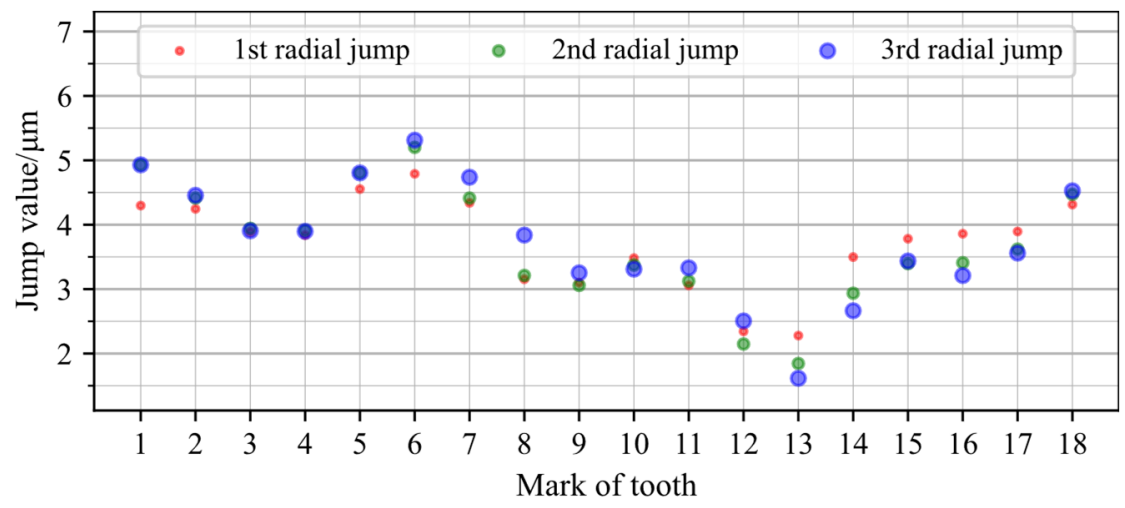

(a)

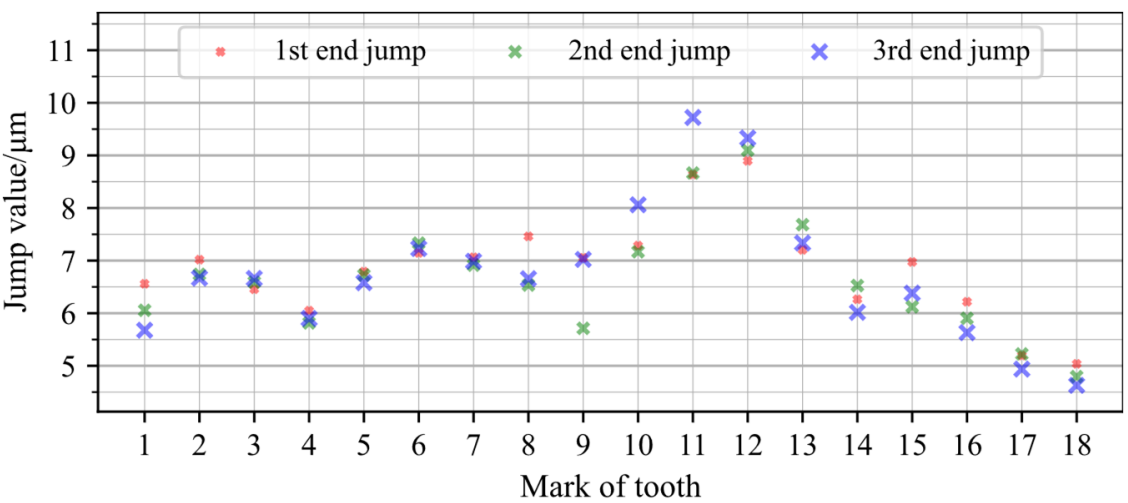

(b)

Figure 13. Test results of experimental group 1 after tooth rotation. (a) Radial jump; (b) end jump.

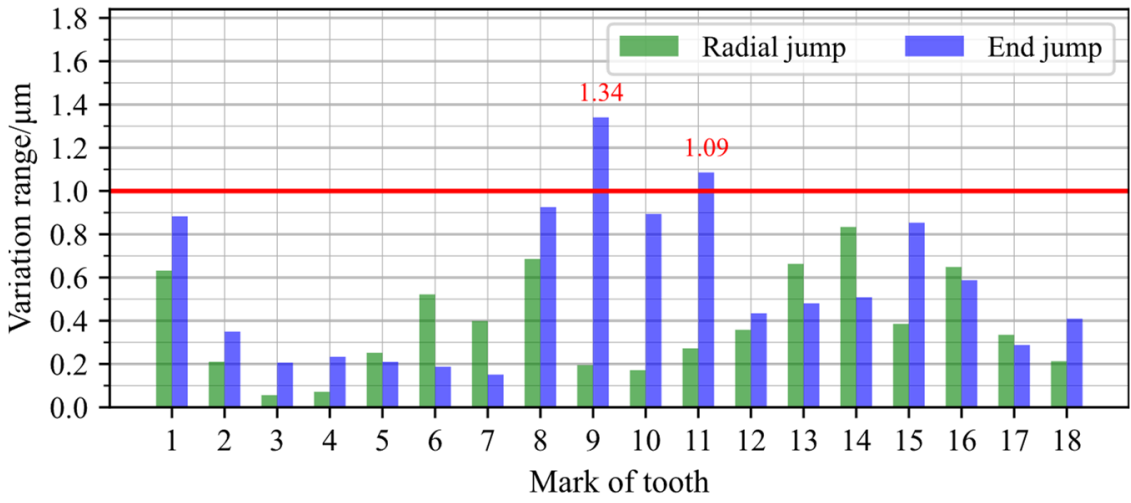

Figure 14. Statistical chart of the three test results of experimental group 1 after turning teeth.

In the group 2 experiment, the upper-gear disc 1 and the lower-gear plate 2 are matched, and the experimental process is the same as that in the group 1 experiment. The results of repeated clamping after non-rotating detection are shown in Figure 15, which indicates that the variations of radial jump and end jump are both less than $1 \mu \mathrm{m}$. The test results of repeated clamping after rotation are shown in Figures 16 and 17. The experimental results show that only the end jump change at tooth 16 is slightly more than $1 \mu \mathrm{m}$. 


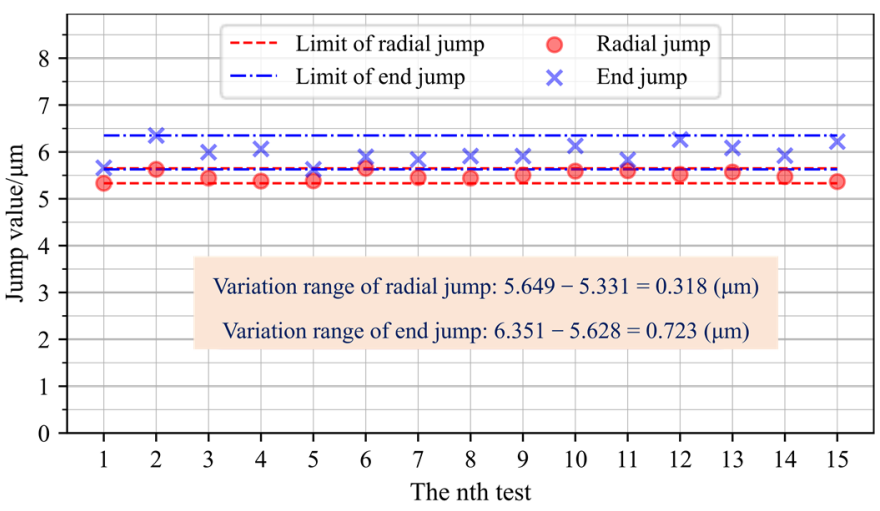

Figure 15. Test results of experimental group 3 without rotating teeth.

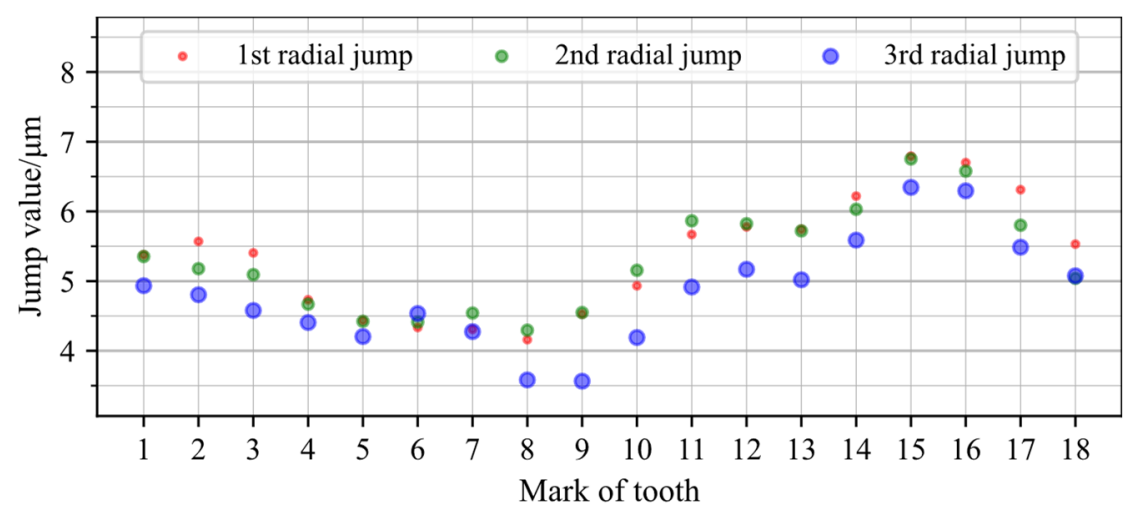

(a)

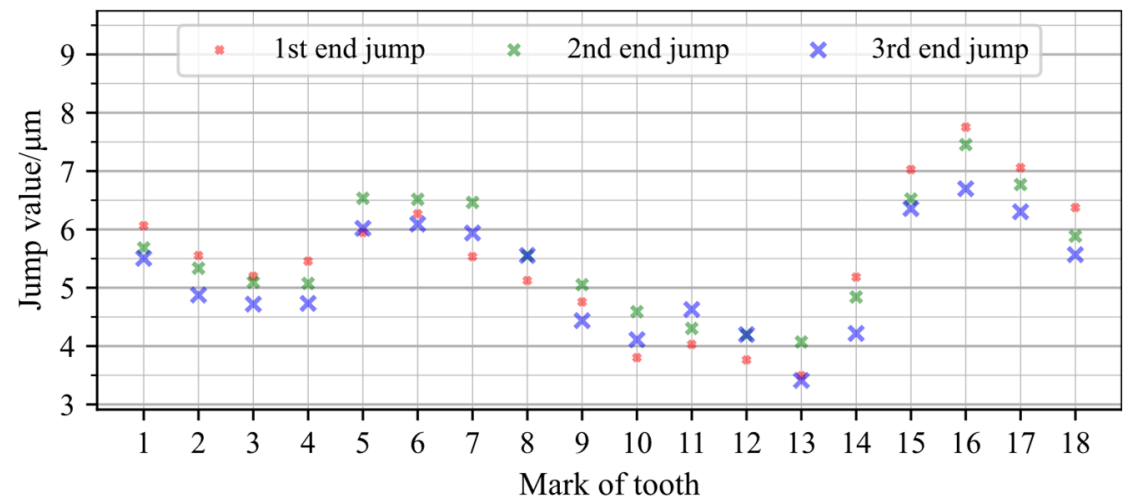

(b)

Figure 16. Test results of experimental group 3 after tooth rotation. (a) Radial jump; (b) end jump.

The results shown in Figures 12 and 15 demonstrate that the repetitive positioning accuracy of the designed quick-change fixture can reach $1 \mu \mathrm{m}$. The results of Figures 14 and 17 can also support the same conclusion. In particular, the different values of run-out at different matching positions reflect the positioning accuracy of the end-toothed disc under the influence of machining errors rather than repetitive positioning accuracy, and the positioning accuracy is consistent with the control precision designed in Section 2.2.1 of this work when formulating tolerances, which also shows the effectiveness of the tolerance design method adopted in this work. 


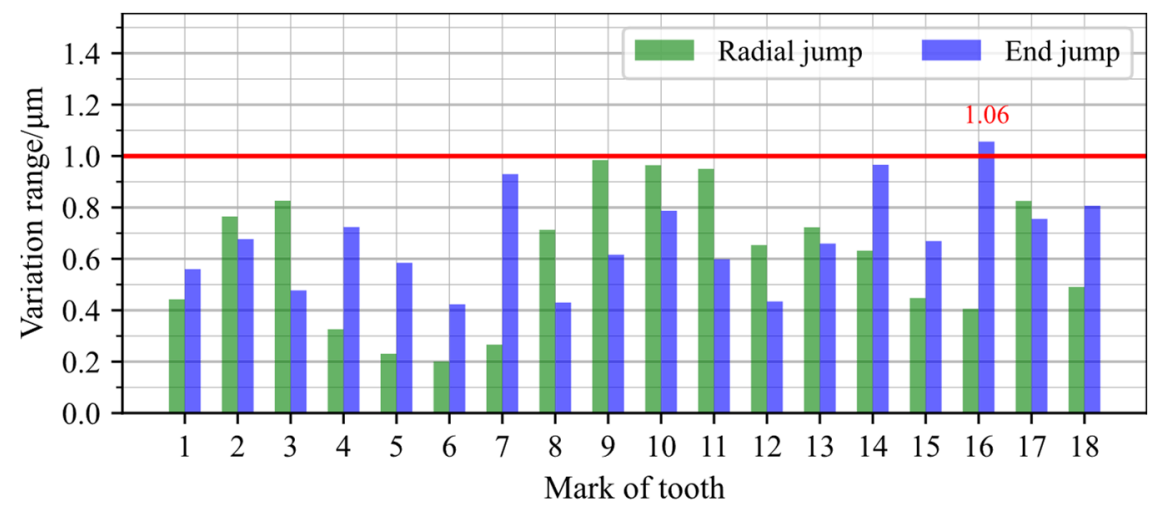

Figure 17. Statistical chart of the three test results of experimental group 2 after turning teeth.

\section{Clamping Simulation and Cylindrical-Cutting Experiment of a Small-Diameter Copper Bar}

The stiffness of the workpiece with a small size is usually weak. In order to evaluate the influence of the use of the quick-change fixture on the machining of weak-stiffness parts, the clamping simulation and cylindrical-cutting experiments of T2 copper bar with a diameter of $4 \mathrm{~mm}$ are carried out.

\subsection{Clamping Simulation of a Small-Diameter Copper Bar}

In order to simplify the simulation conditions, a simple hole-shaft matching method is adopted to simulate ER collet clamping copper rod. The length of the copper rod is set as $40 \mathrm{~mm}$, and the interference mode is used to simulate a clamping length of $20 \mathrm{~mm}$ and an interference amount of $10 \mu \mathrm{m}$. The deformation cloud atlases of the model obtained under the three states of interference-clamping force only, locking force only, and both interference clamping force and locking force-are shown in Figure 18. It can be seen from Figure 18 that the maximum deformation of a workpiece-fixture system for the interference clamping force only, locking force only, and interference clamping force and locking force is $9.381 \mu \mathrm{m}, 0.594 \mu \mathrm{m}$, and $9.292 \mu \mathrm{m}$, respectively. Additionally, the maximum deformation of a workpiece for the interference clamping force only, locking force only, and interference clamping force and locking force is $5.943 \mu \mathrm{m}, 0.444 \mu \mathrm{m}$, and $6.132 \mu \mathrm{m}$, respectively. Therefore, Figure 18 indicates that the maximum deformation of the whole workpiece-fixture system that occurs in the inner hole surface of the simulated fixture in the three cases is close to the set interference value of $10 \mu \mathrm{m}$. The maximum deformation under both interference clamping force and locking force is less than that under interference clamping force only, which is caused by the deformation in opposite directions under the two loads. From the perspective of workpiece deformation only, the maximum deformation occurs at the non-free end of the copper bar, which is mainly caused by interference clamping deformation. The deformation caused by the interference clamping force is much larger than that caused by fast-traveling clamping, either for the whole workpiece-fixture system or only for the workpiece. The simulation results show that the use of a quick-change fixture, rather than directly clamping the workpiece repeatedly, is helpful to reduce the deformation error of weak-stiffness parts caused by repeated clamping.

\subsection{Cylindrical Cutting Experiment of a Small-Diameter Copper Rod}

The use of a quick-change fixture adds a link to the whole machining system. From the perspective of the dynamic model, it can be considered that one or even more groups of mass and damping are added. Moreover, the quick-change fixture is affected by the coupling force fields such as locking force, gravity, centrifugal force, etc. Therefore, the influence of the above factors on the processing of the workpiece is also evaluated. In this section, the ultra-precision diamond turning of T2 copper rod cylindrical surface with a diameter of $4 \mathrm{~mm}$ is carried out by using the designed fixture and the four-axis 
ultra-precision lathe. The experimental configuration of the turning process is shown in Figure 19. The polycrystalline diamond (PCD) tool VCGW110302 (Beijing Worldia Diamond Tools Co., Ltd., Beijing, China) is used. Cutting experiments are performed under a spindle speed $n=900 \mathrm{rpm}$, a cutting depth $a p=10 \mu \mathrm{m}$, a feed $f=10 \mu \mathrm{m}$ per revolution, and a cutting stroke of $10 \mathrm{~mm}$.

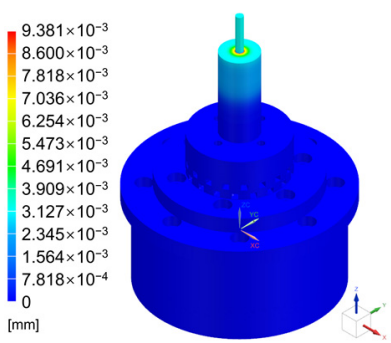

(a)
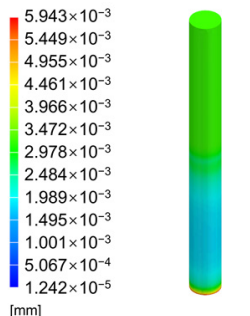

(d)

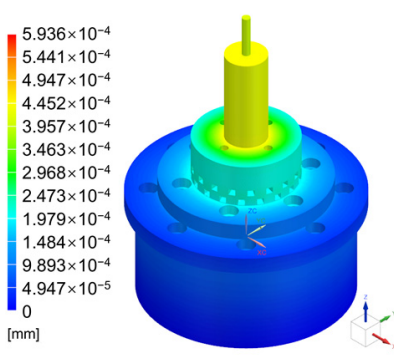

(b)
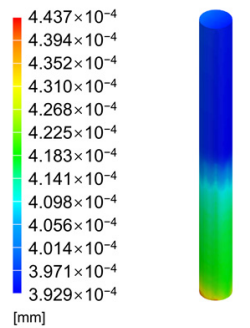

(e)

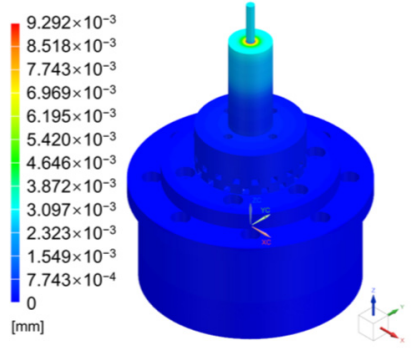

(c)

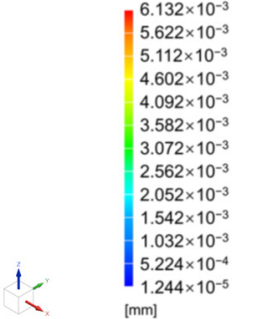

(f)

Figure 18. Simulation contours of $4 \mathrm{~mm}$ diameter copper bar in clamping. (a,d) Interference clamping force only; (b,e) locking force only; (c,f) interference clamping force and locking force.

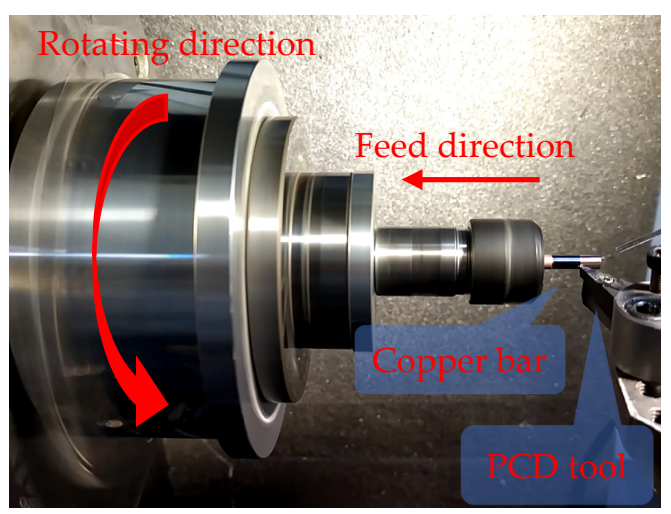

Figure 19. Cutting experiment of cylindrical copper bar with a diameter of $4 \mathrm{~mm}$.

The final machined part is shown in Figure 20a. The machined surface quality of the copper bar is detected by a Zygo white light interferometer, and the results are shown in Figure 20b, which indicates a surface roughness of $130 \mathrm{~nm}$. The knife marks in the figure are clear and stable, and no obvious vibration marks are found. There is no obvious negative impact when using the designed quick-change fixture in the turning process. 


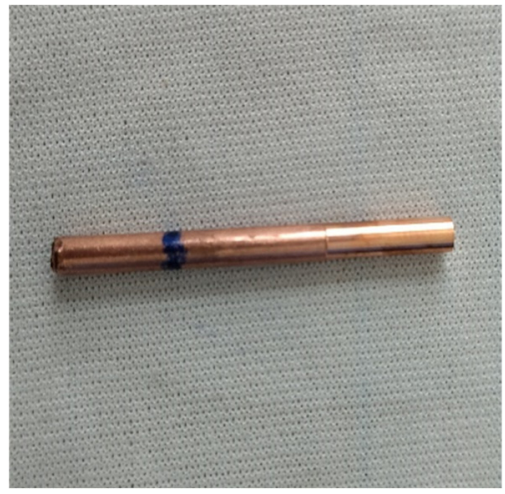

(a)

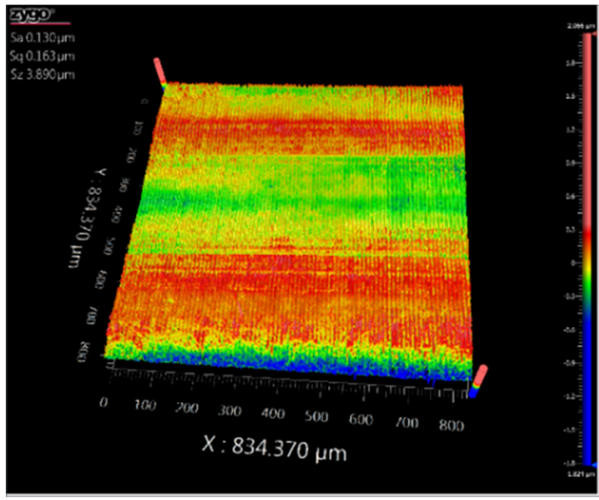

(b)

Figure 20. The finished workpiece and its test result. (a) Picture of the cutting copper bar; (b) surface morphology characterized by white light interferometer.

\section{Conclusions}

In this work, the design, simulation analysis, and experimental testing of the quickchange fixture developed for ultra-precision diamond cutting are carried out, which provide a technical approach to solve the problems of high-precision repetitive clamping and transposition encountered in diamond cutting. The main conclusions of this work are drawn as follows:

(1) A quick-change fixture based on the positioning of the end-toothed disc is developed. The main parameters of two key components of the end-toothed disc and slotted disc spring are designed and calculated. Through the tolerance control of the three-toothprofile machining errors of the end-toothed disc and the rotation symmetry of the overall structure, the positioning accuracy of the designed fixture is guaranteed and can adapt to the rotation condition.

(2) The static analysis and modal analysis of the quick-change fixture are carried out by FE simulation. The results show that the maximum deformation of the designed fixture is about $0.9 \mu \mathrm{m}$ with a minimum natural frequency of $5655.9 \mathrm{~Hz}$, which has good static and dynamic characteristics.

(3) The high-precision detection experiments of multiple groups of quick-change follow fixtures are carried out. The experimental results show that the designed fixture can achieve a precision of $1 \mu \mathrm{m}$. The FE simulation of clamping of a small-diameter copper bar and diamond-turning experiment of the cylindrical surface show that the designed quick-change fixture is helpful to reduce the deformation of a weakstiffness workpiece caused by clamping deformation without a negative effect on workpiece processing.

Author Contributions: Conceptualization, X.Z. and X.C.; data curation, X.C. and Z.H.; funding acquisition, X.Z. and T.S.; project administration, X.Z. and T.S.; software, X.C. and Q.Z.; investigation, Z.H. and Q.Z.; writing-review and editing, X.Z. and X.C. All authors have read and agreed to the published version of the manuscript.

Funding: This research was funded by the Science Challenge Project of China (Grant No. TZ20180060302-01).

Institutional Review Board Statement: Not applicable.

Informed Consent Statement: Not applicable.

Acknowledgments: The authors greatly acknowledge support from the Science Challenge Project (TZ2018006-0302-01).

Conflicts of Interest: The authors declare no conflict of interest. 


\section{References}

1. Guo, D.; Lu, Y. Overview of extreme manufacturing. Int. J. Extrem. Manuf. 2019, 1, 020201. [CrossRef]

2. Wang, Z.F.; Zhang, J.J.; Li, G.; Xu, Z.W.; Zhang, H.J.; Zhang, J.G.; Hartmaier, A.; Fang, F.Z.; Yan, Y.D.; Sun, T. Anisotropy-related machining characteristics in ultra-precision diamond cutting of crystalline copper. Nanomanuf. Metrol. 2020, 3, 123-132. [CrossRef]

3. Gameros, A.; Lowth, S.; Axinte, D.; Nagy-Sochacki, A.; Craig, O.; Siller, H.R. State-of-the-art in fixture systems for the manufacture and assembly of rigid components: A review. Int. J. Mach. Tools Manuf. 2017, 123, 1-21. [CrossRef]

4. Hashemi, H.; Shaharoun, A.M.; Izman, S. Fixture Designers Guidance: A Review of Recent Advanced Approaches. Jordan J. Mech. Ind. Eng. 2014, 8, 377-384.

5. Hashemi, H.; Shaharoun, A.M.; Izman, S. Fixture design automation and optimization techniques: Review and future trends. Int. J. Eng. Trans. B Appl. 2014, 27, 1787-1794.

6. Gonzalo, O.; Seara, J.M.; Guruceta, E.; Izpizua, A.; Esparta, M.; Zamakona, I.; Uterga, N.; Aranburu, A.; Thoelen, J. A method to minimize the workpiece deformation using a concept of intelligent fixture. Robot. Comput. Integr. Manuf. 2017, 48, 209-218. [CrossRef]

7. Sudarshana, S.A.; Kulasekera, A.L.; Jayaweera, N.D. A novel reconfigurable supporting structure for aircraft maintenance applications. In Manufacturing \& Industrial Engineering Symposium; IEEE: New York, NY, USA, 2016.

8. System 3R Cuts BAe Set-Ups from Hours to Minutes. Available online: https:/ / doi.org/10.1108/aeat.1999.12771bab.012 (accessed on 23 September 2021).

9. System 3R Refix Reduces Mould-Making from Weeks to Hours. Available online: https:/ / doi.org/10.1108/aeat.1999.12771aab.007 (accessed on 23 September 2021).

10. System 3R's Macro System Finds New Applications. Available online: https://doi.org/10.1108/aeat.2000.12772aad.010 (accessed on 23 September 2021).

11. Varadarajan, K.M.; Culpepper, M.L. A dual-purpose positioner-fixture for precision six-axis positioning and precision fixturing: Part I. Modeling and design. Precis. Eng. 2007, 31, 276-286. [CrossRef]

12. Varadarajan, K.M.; Culpepper, M.L. A dual-purpose positioner-fixture for precision six-axis positioning and precision fixturing: Part II. Characterization and calibration. Precis. Eng. 2007, 31, 287-292. [CrossRef]

13. Olivari, L. Primjena i princip rada steznih sustava s definiranom nul-točkom. Polytech. Des. 2017, 3, 180-186.

14. Ayatollahi, I.; Brier, J.; Mörzinger, B.; Heger, M.; Bleicher, F. SOA on Smart Manufacturing Utilities for Identification, Data Access and Control. Procedia CIRP 2018, 67, 162-166. [CrossRef]

15. Sitzberger, S.; Liebl, J.; Reitberger, J. Zero-point clamping systems in optical production. In Sixth European Seminar on Precision Optics Manufacturing; SPIE: Bellingham, WA, USA, 2019.

16. Sulz, C.; Brier, J.; Agovic, A.; Bleicher, F. Investigation of the thermal compensation behaviour of zero-point clamping systems. Procedia CIRP 2021, 99, 69-74. [CrossRef]

17. Denkena, B.; Bergmann, B.; Kiesner, J.; Buhl, H. Sensory zero-point clamping system for condition and process monitoring. Procedia CIRP 2021, 96, 359-364. [CrossRef]

18. Zhao, X.; Tan, R.; Wang, Z.; Zou, X.; Hu, Z.; Sun, T. The Design and Implementation of a High-Precision Positioner Fixture. Micromachines 2021, 12, 1227. [CrossRef] [PubMed]

19. Urgo, M.; Terkaj, W.; Cenati, C.; Giannini, F.; Monti, M.; Pellegrinelli, S. Zero-point fixture systems as a reconfiguration enabler in flexible manufacturing systems. Comput. Des. Appl. 2016, 13, 684-692. [CrossRef]

20. Kandera, M.; Císar, M.; Kuric, I. Modification of Clamping System Designated for Automatic Workpiece Exchange. Manuf. Technol. 2019, 19, 414-418. [CrossRef]

21. Pellegrinelli, S.; Terkaj, W.; Urgo, M. A concept for a pallet configuration approach using zero-point clamping systems. Procedia CIRP 2016, 41, 123-128. [CrossRef]

22. Urgo, M.; Terkaj, W.; Giannini, F.; Pellegrinelli, S.; Borgo, S. Exploiting modular pallet flexibility for product and process co-evolution through zero-point clamping systems. In Factories of the Future; Springer: Cham, Switzerland, 2019 ; pp. 57-82.

23. Anand, H. Nonlinear Aeroelastic Analysis of a High Aspect Ratio Wing in NASTRAN. Master's Thesis, Delft University of Technology, Delft, The Netherlands, 29 April 2019.

24. Nekhoroshev, M.V.; Meshcheryakov, A.V.; Bezsonov, K.A.; Shulepov, A.P. Design Optimization of Machine Accessories through Analysis of their Elements Deformation in NX Nastran. In Proceedings of the International Conference "Actual Issues of Mechanical Engineering" (AIME 2018), Novosibirsk, Russia, 19-21 April 2018. 